\title{
JGZ-richtlijn Heupdysplasie
}

\author{
A. A. J. Konijnendijk · J. A. Deurloo • C. I. Lanting · M. M. Boere-Boonekamp
}

Published online: 13 July 2018

(C) Bohn Stafleu van Loghum is een imprint van Springer Media B.V., onderdeel van Springer Nature 2018

Samenvatting In januari 2018 is de jeugdgezondheidszorg (JGZ)-richtlijn Heupdysplasie gepubliceerd. Het doel van deze richtlijn is het ondersteunen van het handelen van de JGZ-professional bij de vroegtijdige opsporing van heupdysplasie, door geprotocolleerde screening en tijdige verwijzing voor aanvullende diagnostiek.

Trefwoorden heupdysplasie - screening - jeugdgezondheidszorg

\section{Inleiding}

\section{Aard van de aandoening}

Bij heupdysplasie is sprake van een onderontwikkeling (dysplasie) van het heupgewricht. Internationaal wordt sinds begin jaren '90 van de twintigste eeuw in plaats van de term heupdysplasie de term Developmental Dysplasia of the Hip (DDH) gebruikt om het dynamische karakter van de aandoening te benadrukken [1].

$\mathrm{DDH}$ kan in verschillende graderingen aanwezig zijn (fig. 1). Bij de geboorte kan er sprake zijn van instabiele, luxeerbare heupen. De heupkop sluit dan onvoldoende aan bij de heupkom. Meestal zullen deze heupen in de eerste weken spontaan herstellen. Ze kunnen echter ook op verschillende tijdstip-

A. A. J. Konijnendijk $(\bowtie) \cdot$ M. M. Boere-Boonekamp Vakgroep Health Technology and Services Research, Universiteit Twente, Enschede, Nederland

a.a.j.konijnendijk@utwente.nl

J. A. Deurloo · C. I. Lanting

TNO Child Health, Leiden, Nederland

J. A. Deurloo

GGD Hollands Noorden, Alkmaar, Nederland pen daarna (sub)luxeren. Soms gebeurt dit pas als het kind gaat lopen.

Het is ook mogelijk dat er een verstoring van de normale ontwikkeling van het gewricht is opgetreden tijdens de zwangerschap of na de bevalling. Dit kan leiden tot een te steile en ondiepe heupkom, en een abnormaal naar ventraal gedraaide heupkop (dysplasie zonder luxatie, fig. 1b). De heupkop kan dan gemakkelijk uit de ondiepe kom glijden (dysplasie met subluxatie, fig. 1c). De meest ernstige vorm van $\mathrm{DDH}$ is dysplasie met luxatie (fig. 1d): de heupkop bevindt zich dan volledig buiten de heupkom.

\section{Epidemiologie}

In Nederland komt DDH voor bij $1-4 \%$ van de zuigelingen van 0-6 maanden [3]; in ongeveer $20 \%$ van de gevallen betreft het dubbelzijdige DDH [4]. De linkerheup is ongeveer 1,5 keer zo vaak aangedaan als de rechterheup [5], waarschijnlijk vanwege de meest voorkomende ligging in de baarmoeder, waardoor de linkerheup in adductie tegen de moederlijke wervelkolom wordt gedrukt [6, 7]. DDH komt 3-4 keer zo vaak voor bij meisjes als bij jongens $[5,8]$. Van alle zuigelingen met DDH heeft $10-27 \%$ een of meer risicofactoren anders dan vrouwelijk geslacht [9]. Bij enkele syndromen, waaronder het syndroom van Down [10], en enkele neuromusculaire stoornissen die zich kenmerken door spierzwakte of spasticiteit, zoals spina bifida [11], komt DDH vaker voor.

\section{Natuurlijk beloop}

Het natuurlijke beloop van de neonataal luxeerbare heup is meestal gunstig, $60-80 \%$ herstelt spontaan. De overige gevallen gaan zonder behandeling over in een dysplasie en eventueel in een (sub)luxatie [12]. De prognose hiervan is veelal ongunstig. Bij een dysplasie 


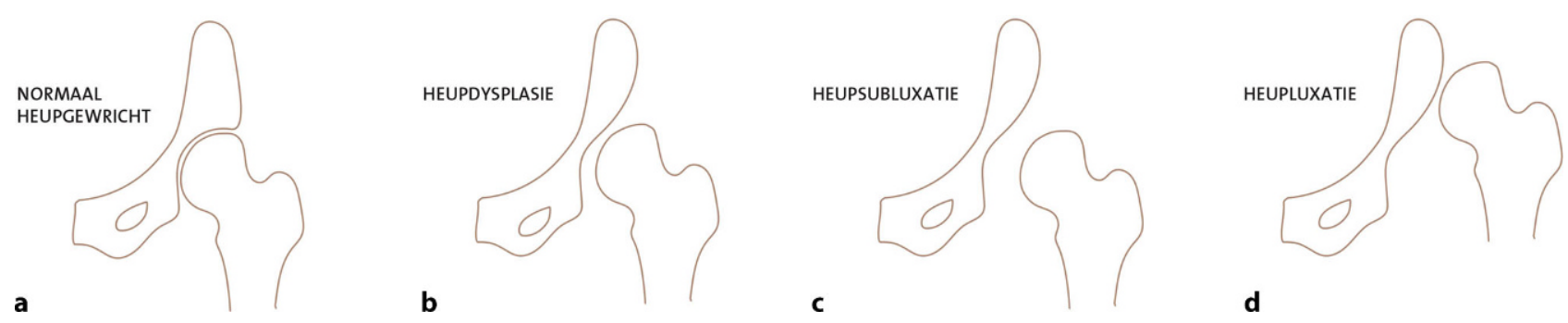

Figuur 1 Vereenvoudigde weergave van een normaal heupgewricht (a) en de verschillende graderingen van DDH (b-d) [2]

van de heup zonder (sub)luxatie ontwikkelt ongeveer $70 \%$ op volwassen leeftijd vroegtijdige slijtage, ofwel coxartrose [13-15]. Bij een ge(sub)luxeerde heup treden op de leeftijd van 2 à 3 maanden vaak al veranderingen ten gevolge van de (sub)luxatie op, zoals een verkorting van de heupadductoren.

\section{Gevolgen voor het dagelijks leven}

Zonder behandeling kan DDH leiden tot ernstige invaliditeit. Bij luxatie van een heup ontstaat een verschil in beenlengte, uiteindelijk tot circa 6 centimeter. Het kind zal gaan trekken met een been en mank lopen. Bij een dubbelzijdige luxatie ontwikkelt het kind een holle rug en kan het gaan lopen met een eendengang of waggelgang. Op (jong)volwassen leeftijd zullen meestal pijn en invalidering optreden door coxartrose $[4,13,14]$. De kans op coxartrose is lager wanneer kinderen vroeg worden behandeld voor DDH.

\section{Behandeling}

De behandeling van een zuigeling met DDH zonder (sub)luxatie bestaat uit het in flexie- en spreidstand houden van de heupen met een spreidmiddel, aanvankelijk gedurende tenminste 23 uur per dag. Hierdoor wordt de heupkop goed in de heupkom geplaatst. Meestal duurt de spreidbehandeling meerdere maanden in het eerste levensjaar van het kind.

Als een dysplasie gepaard gaat met een (sub)luxatie van de heupkop, zal eerst repositie van de heupkop moeten plaatsvinden. Repositie wordt gevolgd door stabilisatie van de heupen in flexie en abductie gedurende enige maanden met een gipsbroek. Daarna kan nog langdurige spreidbehandeling plaatsvinden [7]. Wanneer een dysplasie op latere leeftijd wordt ontdekt, of wanneer sprake is van restdysplasie na behandeling van een luxatie, kan vaak alleen nog door een bekkenosteotomie een goede overdekking van de heupkop worden verkregen, over het algemeen pas na de leeftijd van 3 jaar [7].

\section{Richtlijnontwikkeling}

De JGZ-richtlijn Heupdysplasie [16] is gebaseerd op een knelpuntenanalyse uitgevoerd door het Centraal BegeleidingsOrgaan (CBO) [17]. Deze knelpuntenana- lyse resulteerde in tien uitgangsvragen die in deze richtlijn worden beantwoord.

De richtlijn is ontwikkeld volgens de methode van evidence-based richtlijnontwikkeling (EBRO) [18]. Op basis van het beschikbare bewijs in de wetenschappelijke literatuur, grijze literatuur (waaronder bestaande richtlijnen), handboeken en expertopinie zijn concrete aanbevelingen geformuleerd voor de praktijk. De richtlijntekst is goedgekeurd en geautoriseerd voor gebruik in de JGZ door de Richtlijn Adviesen Autorisatie Commissie (RAC) van het Nederlands Centrum Jeugdgezondheid (NCJ).

De doelgroep van de richtlijn betreft jeugdartsen en jeugdverpleegkundigen. Daar waar 'jeugdarts' staat, kan ook 'verpleegkundig specialist' worden gelezen.

\section{Aanbevelingen in de richtlijn}

De richtlijn geeft de aanbevelingen voor screening, handelen en verwijzen (thema 1), voor communicatie tussen ouders en JGZ-professionals (thema 2), en voor samenwerking tussen de disciplines die betrokken zijn bij de opsporing, behandeling en nazorg van kinderen met DDH (thema 3). De aanbevelingen voor

\section{Anamnese}

1. Jeugdartsen en jeugdverpleegkundigen kennen de risicofactoren voor DDH. Dit zijn: belaste familieanamnese, dat wil zeggen DDH en/of coxartrose voor de leeftijd van 50 jaar bij eerste(ouders, zussen, broers) of tweedegraads (grootouders, tantes, ooms) familieleden; stuitligging vastgesteld na week 32 van de zwangerschap ongeacht de duur en periode van de stuitligging, stuitligging bij de bevalling, en het strak inbakeren van het onderlichaam met de heupen en de knieën gestrekt.

2. In de eerste 3 levensmaanden vraagt de jeugdverpleegkundige en/of jeugdarts tweemaal na of er sprake is van risicofactoren voor DDH en registreert de bevindingen in het Digitaal Dossier JGZ.

3. De jeugdarts stelt vast of sprake is van risicofactoren voor DDH waarvoor verwijzing voor beeldvormend onderzoek op de leeftijd van 3 maanden aangewezen is. 


\section{Richtlijn}

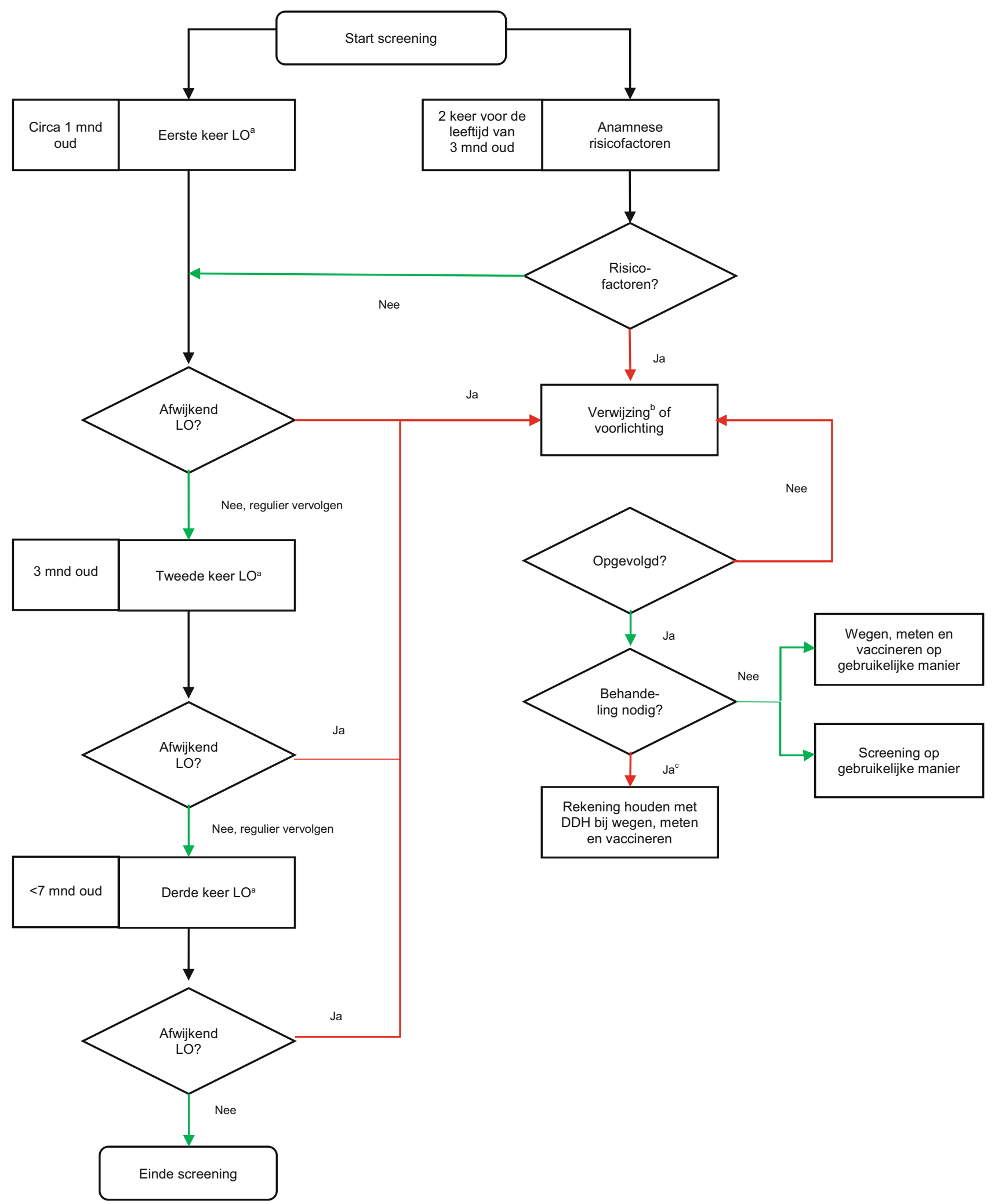

Figuur 2 Screeningsprotocol voor DDH bij kinderen tot en met 6 maanden oud ( $L O$ Lichamelijk onderzoek, $D D H$ Devel-

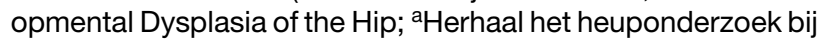
voorkeur binnen 2-4 weken wanneer het heuponderzoek niet goed is gelukt, bijvoorbeeld omdat het kind huilerig, hangerig of onrustig is; 'Verwijzing gaat altijd samen met berichtgeving aan de huisarts en uitleg aan ouders over de verwijzing. Het

verwijsprotocol (leeftijd 0 tot en met 6 maanden) beschrijft de precieze verwijscriteria; ' $D$ e jeugdarts geeft aan dat ouders zo nodig voor vragen rond de behandeling terecht kunnen bij de (kinder)orthopeed, de orthopedisch instrumentmaker, de JGZ en de patiëntenvereniging Vereniging Afwijkende Heupontwikkeling (VAH)) 
Aanbevelingen voor screening, handelen en verwijzen

\section{Lichamelijk onderzoek}

Leeftijdsperiode 4 weken tot en met 6 maanden:

1. De jeugdarts voert bij elk kind aan het einde van de eerste levensmaand heuponderzoek uit, een tweede keer bij voorkeur bij 3 maanden en een derde keer voor de leeftijd van 7 maanden. Bij prematuur geboren kinderen is het streven om voor de gecorrigeerde leeftijd van 7 maanden 3 onderzoeken uit te voeren, en bij langdurige ziekenhuisopname 2 onderzoeken, in samenspraak met kinderarts en ouders.

2. Het heuponderzoek bestaat uit: beoordeling van de abductie van de heupen, en vergelijking van de kniehoogte.

3. Het heuponderzoek wordt uitgevoerd in een warme omgeving met warme handen, zodat de spieren van het kind zoveel mogelijk ontspannen zijn. Het onderzoek vindt plaats op een vlakke, warme en stevige onderlaag, bijvoorbeeld een harde (yoga)mat van ongeveer $1 \mathrm{~cm}$ dik met daarop een handdoek; een zacht (aankleed)kussen dient te worden verwijderd. De beoordeling van de abductie en het vergelijken van de kniehoogte vindt plaats in rugligging. Het kind is voor het onderzoek volledig ontkleed met de luier af en ligt recht en ontspannen. Recht liggen wil zeggen: wervelkolom en bekken zijn recht, gezicht van het kind bevindt zich in de middenpositie, kind kijkt recht naar voren, en de lijn tussen de spinae iliaca staat loodrecht op de lichaamsas of de bil-vulvanaad staat verticaal ten opzichte van de onderlaag. De onderzoeker staat aan het voeteneind. Herhaal het heuponderzoek bij voorkeur binnen 2 tot 4 weken wanneer het heuponderzoek niet goed is gelukt, bijvoorbeeld omdat het kind huilerig, hangerig of onrustig is.

\section{Leeftijdsperiode 7 maanden tot 18 jaar:}

1. In de leeftijdsperiode 7 maanden tot 2 jaar wordt het heuponderzoek (zie boven) uitgevoerd, als de jeugdarts lichamelijk onderzoek verricht.

2. Na de leeftijd van 2 jaar vindt onderzoek van de heupen alleen op indicatie door de jeugdarts plaats, dat wil zeggen als er vragen, zorgen, klachten of opvallende observaties zijn van ouders/ kind en/of jeugdverpleegkundige en/of jeugdarts.
3. Vanaf het moment dat het kind zelfstandig loopt, vindt altijd als eerste onderzoek in staande houding plaats: looppatroon, luchtfiguur onder het perineum, lendenlordose, beenlengte (vanaf de leeftijd van 2 jaar). Bij afwijkende bevindingen in staande houding of bij specifieke klachten wordt het onderzoek uitgebreid met onderzoek van de abductie en kniehoogte in liggende houding.

\section{Verwijzing}

Leeftijdsperiode 4 weken tot en met 6 maanden:

1. Bij een belaste familieanamnese en/of stuitligging na week 32 van de zwangerschap ongeacht de duur en periode van de stuitligging en/of stuitligging bij de bevalling verwijst de jeugdarts het kind voor beeldvormend onderzoek op de leeftijd van 3 maanden. Verwijzing vindt plaats ongeacht de uitslag van het lichamelijk onderzoek van de heupen.

2. Bij een afwijkend onderzoek van de heupen verwijst de jeugdarts het kind voor diagnostisch onderzoek: bij een abductiebeperking, dat wil zeggen abductie $<70$ graden; een abductieverschil van $\geq 20$ graden; en/of een duidelijk zichtbaar kniehoogteverschil.

a. Bij een vermoeden van dysplasie met luxatie verwijst de jeugdarts op dat moment naar de (kinder)orthopeed met het verzoek het kind binnen 2 weken te onderzoeken.

b. Bij een vermoeden van dysplasie zonder luxatie verwijst de jeugdarts voor beeldvormend onderzoek op de leeftijd van 3 maanden, of, indien het vermoeden na 3 maanden ontstond, binnen 2 weken na verwijzing.

3. Wanneer twee keer achter elkaar twijfel bestaat over de uitkomst van het lichamelijk onderzoek, bijvoorbeeld vanwege een huilend, hangerig of onrustig kind, verwijst de jeugdarts het kind voor beeldvormend onderzoek met het verzoek het kind binnen 2 weken te onderzoeken.

4. Wanneer sprake is van herhaalde afwijkende bevindingen bij lichamelijk onderzoek, terwijl beeldvormend onderzoek een normale uitslag gaf, verwijst de jeugdarts naar de (kinder)orthopeed met het verzoek het kind binnen 2 weken te onderzoeken.

5. Het strak inbakeren van het onderlichaam van het kind met de heupen en knieën gestrekt is als enige bevinding geen indicatie voor verwijzing, maar wel een reden om de overige onderdelen van het lichamelijk onderzoek extra alert uit te voeren. Extra alert wil zeggen dat de onderzoeker geen twijfel mag hebben over de betrouwbaarheid van het onderzoek (abductie en kniehoogte) en zo nodig laagdrempelig een extra contactmoment ter controle afspreekt. 
6. Bij prematuriteit gelden de volgende aanbevelingen. Bij risicofactoren en/of een vermoeden van dysplasie zonder luxatie is beeldvormend onderzoek wenselijk na de gecorrigeerde leeftijd van 3 maanden. Indien het vermoeden ontstaat na de gecorrigeerde leeftijd van 3 maanden, is beeldvormend onderzoek binnen 2 weken wenselijk. De casemanager (kinderarts, jeugdarts of huisarts) van het kind beslist samen met de ouders op welk moment de verwijzing plaatsvindt. Bij de beslissing spelen belastbaarheid van kind en ouders, mate van prematuriteit en ernst van de afwijkende bevindingen een rol. Bij een vermoeden van dysplasie met luxatie verwijst de jeugdarts op dat moment naar de (kinder)orthopeed met het verzoek het kind binnen 2 weken te onderzoeken.

Leeftijdsperiode 7 maanden tot 18 jaar:

Bij vaststelling door de jeugdarts van afwijkende bevindingen die kunnen wijzen op DDH bij een kind in de leeftijdsperiode vanaf 7 maanden tot 18 jaar vindt verwijzing naar de (kinder)orthopeed plaats, met het verzoek het kind binnen 2 weken te onderzoeken.

\section{Aandachtspunten voor JGZ tijdens behandeling}

1. De JGZ verricht geen lengtemeting als een kind een spreidbehandeling ondergaat. Wegen gebeurt bij voorkeur zonder spreidmiddel (als dit af mag van de (kinder)orthopeed) en anders met spreidmiddel.

2. De plek waar de vaccinatie plaatsvindt (bovenbeen of bovenarm) wordt, na het geven van uitleg, in overleg met ouders bepaald. Bij kinderen met een gipsbroek is de bovenarm de aangewezen plek voor de vaccinatie. Bij een afneembare spreidmiddelbehandeling gaat de voorkeur uit naar het bovenbeen als plek voor de vaccinatie.

\section{Voorlichting en instructie}

Als de ouder aangeeft dat het onderlichaam van het kind wordt ingebakerd met de heupen en de knieën gestrekt of dat men dit van plan is, wordt uitgelegd dat het strak inbakeren van het onderlichaam gepaard gaat met een verhoogd risico op DDH en wordt instructie aangeboden over de veilige manier van inbakeren (zie het boek 'Inbakeren brengt rust' van Ria Blom [19]). thema 1, overgenomen uit de richtlijn, staan hieronder weergegeven [16]. Zie ook fig. 2. Voor de aanbevelingen voor thema 2 en 3 wordt verwezen naar de richtlijn op website.

\section{Praktijktest}

In februari tot en met april 2017 is de conceptrichtlijn getest bij vier praktijkorganisaties. In totaal namen 45 professionals deel aan de praktijktest. Het waren 40 jeugdartsen (89\%) en 5 jeugdverpleegkundigen $(11 \%)$. De deelnemers gaven aan de kernelementen in de richtlijn in het algemeen duidelijk te vinden, passend bij de huidige werkwijze en goed onderbouwd. Daarnaast werden diverse suggesties gegeven voor aanpassingen in de tekst, bleek er behoefte aan beeldmateriaal en aan het oefenen van praktische vaardigheden, en werden zorgen geuit over de grote variatie in de werkwijze van ziekenhuizen en specialisten. Naar aanleiding van de praktijktest zijn de richtlijn en de stroomdiagrammen op diverse punten aangepast.

\section{Randvoorwaarden voor succesvolle implementatie}

Voor de landelijke implementatie van de richtlijn is een inhoudelijke instructie over de richtlijn van ongeveer 2,5 uur nodig. Voorafgaand aan de instructie dienen de JGZ-professionals de richtlijn te lezen, hiervoor hebben zij ongeveer 2 uur leestijd nodig. Tijdens de instructie dient er ruimte te zijn voor het oefenen van praktische vaardigheden voor de jeugdartsen. Ook dient er aandacht te zijn voor veilig inbakeren, het huisbezoek door de jeugdverpleegkundige en het navragen of ouders een afspraak hebben gemaakt voor beeldvormend onderzoek. Naast de inhoudelijke instructie/scholing wordt geadviseerd om de richtlijn te bespreken op team- of discipline-overleggen. Op deze manier kunnen JGZ-professionals in een kleine setting hun ervaringen, knelpunten en daarbij gehanteerde oplossingen met elkaar bespreken.

De richtlijn is na autorisatie verspreid en bekend gemaakt bij de beroepsorganisaties van huisartsen, kinderartsen, radiologen en orthopeden. De richtlijn is geautoriseerd door het Nederlands Huisartsen Genootschap (NHG) en de Nederlandse Vereniging voor Kindergeneeskunde (NVK). Aanbevolen wordt dat JGZ-organisaties de richtlijn tijdens regionale overleggen met ketenpartners bespreken.

\section{Meer informatie?}

De JGZ-richtlijn Heupdysplasie is ontwikkeld door TNO en de Universiteit Twente, samen met een multidisciplinaire werkgroep. De richtlijn is gefinancierd door ZonMw. Voor de volledige tekst van de richtlijn, en de ondersteunende producten zoals stroomdiagrammen, factsheet, PowerPoint-presentatie, BDS- 
protocol en e-learning, zie: www.jgzrichtlijnen.nl. Hier vindt $\mathrm{u}$ ook gegevens over de auteurs en de totstandkoming van de richtlijn. De richtlijn is opgenomen in de app 'JGZ-richtlijnen' (gratis te downloaden voor iOS en Android).

\section{Literatuur}

1. Klisic PJ. Congenital dislocation of the hip-a misleading term: brief report. JBone Joint Surg Br. 1989;71:136.

2. Kingma MJ. Nederlands Leerboek der orthopedie. Utrecht: Bohn, Scheltema \& Holkema; 1977.

3. Boere-Boonekamp MM. Screening for developmental dysplasia of the hip (dissertation). 1996.

4. Jackson JC, Runge MM, Nye NS. Common questions about developmental dysplasia of the hip. Am Fam Physician. 2014;90:843-50.

5. Ortiz-Neira CL, Paolucci EO, Donnon T. A meta-analysis of common risk factors associated with the diagnosis of developmental dysplasia of the hip in newborns. Eur J Radiol. 2012;81:e344-e51.

6. Tönnis D. Congenital dysplasia and dislocation of the hip in children and adults. Berlin: Springer; 1987.

7. Boere-Boonekamp MM, Mostert AK. Dysplastische heupontwikkeling. Basisboek Jeugdgezondheidszorg in Nederland. Maarssen: Elsevier;2010. pag. 139-52.

8. De Hundt M, Vlemmix F, Bais JM, et al. Risk factors for developmental dysplasia of the hip: a meta-analysis. Eur J Obstet Gynecol Reprod Biol. 2012;165:8-17.

9. American Academy of Pediatrics. Screening for developmental dysplasia of the hip: recommendation statement. Pediatrics. 2006;117:898-902.

10. Shaw ED, Beals RK. The hip joint in Down's syndrome. A study of its structure and associated disease. Clin Orthop Relat Res. 1992;278:101-7.
11. Broughton NS, Menelaus MB, Cole WG, Shurtleff DB. The natural history of hip deformity in myelomeningocele. JBone Joint Surg Br. 1993;75:760-3.

12. Visser JD. Pluis of niet pluis. Een leidraad voor de eerste lijn gezondheidszorg. Groningen: Styx; 2012.

13. Wedge JH, Wasylenko MJ. The natural history of congenital dislocation of the hip: a critical review. Clin Orthop Relat Res. 1978;137:154-62.

14. Hasegawa Y, Iwata H, Mizuno M, Genda E, Sato S, Miura T. The natural course of osteoarthritis of the hip due to subluxation or acetabular dysplasia. Arch Orthop Trauma Surg. 1992;111:187-91.

15. Ziegler J, Thielemann F, Mayer-Athenstaedt C, Gunther KP. The natural history of developmental dysplasia of the hip. A meta-analysis of the published literature. Orthopäde. 2008;37(515-6):8-24.

16. Boere-Boonekamp MM, KonijnendijkAAJ, BroerseA, Deurloo JA, Lanting CI. JGZ-richtlijn Heupdysplasie. Leiden/ Enschede/Utrecht: TNO/Universiteit Twente/NCJ;2018.

17. De Argumentenfabriek, CBO. Knelpuntenanalyses Jeugdgezondheidszorg. Utrecht: CBO;2014.

18. CBO Kwaliteitsinstituut voor de Gezondheidszorg. Evidence-based Richtlijnontwikkeling. Handleiding voor werkgroepleden. 2007.

19. Blom R. Inbakeren brengt rust. Een handleiding voor het inbakerenvan jekind. 2017.

A.A.J Konijnendijk, psycholoog veiligheid \& gezondheid, onderzoeker

J. A. Deurloo, arts maatschappij \& gezondheid, jeugdarts en stafarts, richtlijnontwikkelaar

C. I. Lanting, arts n.p., epidemioloog, richtlijnontwikkelaar

M. M. Boere-Boonekamp, arts maatschappij \& gezondheid, universitair hoofddocent 